\title{
Pregnancy established in an infertile patient after transfer of a donated embryo fertilised in vitro
}

\author{
ALAN TROUNSON, JOHN LEETON, MANDY BESANKO, CARL WOOD, ANGELO CONTI
}

\begin{abstract}
In vitro fertilisation after stimulation of the ovulatory cycle has led to successful pregnancy. If more oocytes are recovered than are needed they may be left unfertilised, preserved, or donated to a recipient couple from whom oocytes cannot be obtained. A case of human pregnancy initiated by transfer of a donated embryo fertilised in vitro is reported. The donor was a 42 year old woman with primary infertility from whom six follicles were aspirated after stimulation of the ovulatory cycle. The recipient was a 38 year old infertile woman who had undergone several unsuccessful attempts for artificial insemination from a donor. Five oocytes were recovered from the donor's six follicles, four of which were inseminated with spermatozoa of the donor's husband and the fifth with a frozen sample of semen. Three of the four embryos fertilised by her husband were returned to the donor and the fifth was transferred to the recipient. No pregnancy was recorded in the donor, but pregnancy was confirmed in the recipient, though spontaneous abortion occurred after 10 weeks.

This case will give useful information for further study of in vitro fertilisation, but also raises many ethical issues.
\end{abstract}

\section{Introduction}

In vitro fertilisation after stimulation of the ovulatory cycle with clomiphene citrate or human menopausal gonadotrophin ${ }^{12}$ provides the opportunity to obtain a number of oocytes that

Department of Obstetrics and Gynaecology, Monash University, Melbourne, Australia 3000

ALAN TROUNSON, MSC, PHD, senior lecturer

JOHN LEETON, FRACS, FRCOG, associate professor

MANDY BESANKO, BSC, technical officer

CARL WOOD, FRCS, FRCOG, professor

ANGELO CONTI, MD, visiting research fellow

Correspondence to: $\mathrm{Dr} A$ Trounson, Department of Obstetrics and Gynaecology, Monash University, Queen Victoria Medical Centre, 172 Lonsdale Street, Melbourne, Australia 3000 may be fertilised ${ }^{3}$ and develop to normal fetuses and babies ${ }^{4}$ after replacement in the uterus. ${ }^{6}$ We normally advise patients undergoing in vitro fertilisation that not more than three embryos should be transplanted back in the uterus because of the obstetric risks associated with the potential establishment of a triplet or quadruplet pregnancy. If more than three oocytes are recovered the patients are given the following alternatives: not fertilising all the recovered oocytes, thereby limiting the number of potential embryos to the number desired for replacement; preserving the oocytes or embryos excess to that desired for replacement by techniques of embryo preservation ${ }^{78}$; or donating oocytes to a recipient couple from whom we are unable to obtain oocytes because of severe pelvic disorders, risk of genetic disease, physical risk to the patient of in vitro fertilisation procedures, ovarian dygenesis, failed ovulatory stimulation, or the absence of ovaries.

The donation of oocytes is completely anonymous and certain steps are taken to preserve the anonymity of donor and recipient. Any embryo resulting from the donation of an oocyte is transferred in a completely separate institution from where the donor is treated and her embryos transferred. The identity of the donor is known only to the clinician in charge and the scientist conducting the laboratory procedures. Neither the recipient nor the donor is informed of the resulting outcome of embryo development, transfer, or pregnancy in the other patient. Informed consent for both donation and receipt of oocytes or embryos is obtained in writing from both parties.

We report the first case of a human pregnancy initiated by transfer of a donated embryo fertilised in vitro.

\section{Patients and methods}

DONOR

The donor was a 42 year old woman complaining of primary infertility for four years. Regular ovulation was confirmed during 28 day cycles. Laparoscopy showed a blocked left fallopian tube and a tortuous patent right tube. There was a pedunculated fibromyoma 3 $\mathrm{cm}$ in diameter attached to the fundus of the uterus, though the uterine cavity felt smooth on curettage. The ovaries were normal and fully accessible. Analysis of her husband's semen showed consistent oligospermia with concentrations from 7 to $12 \times 10^{6}$ spermatozoa $/ \mathrm{ml}$ and sperm motilities from 40 to $50 \%$.

The donor was given $100 \mathrm{mg}$ clomiphene citrate (Clomid; Merrell, 
Sydney, Australia) for two days starting on the first day of her menses and $150 \mathrm{mg}$ clomiphene for the next three days. In addition she was given 75 IU human menopausal gonadotrophins (Humagon; Organon, Sydney, Australia) daily from day 2 (second day after menses began) to day 6,150 IU on days 7 to 9 , and 75 IU on day 10 . The daily dosage of human menopausal gonadotrophins was determined by the changes in plasma concentrations of oestradiol $17 \beta$ (fig 1). The patient had a spontaneous surge of luteinising hormone at 0400 hours on day 14 (fig 2) as assessed by radioimmunoassay of three hourly urine collection. ${ }^{9}$ Laparoscopy was timed for 23 hours after the start of the surge of luteinising hormone. Six large follicles were aspirated and five oocytes recovered. The oocytes were incubated in $1 \mathrm{ml}$ culture medium for seven hours before being inseminated. ${ }^{3}$

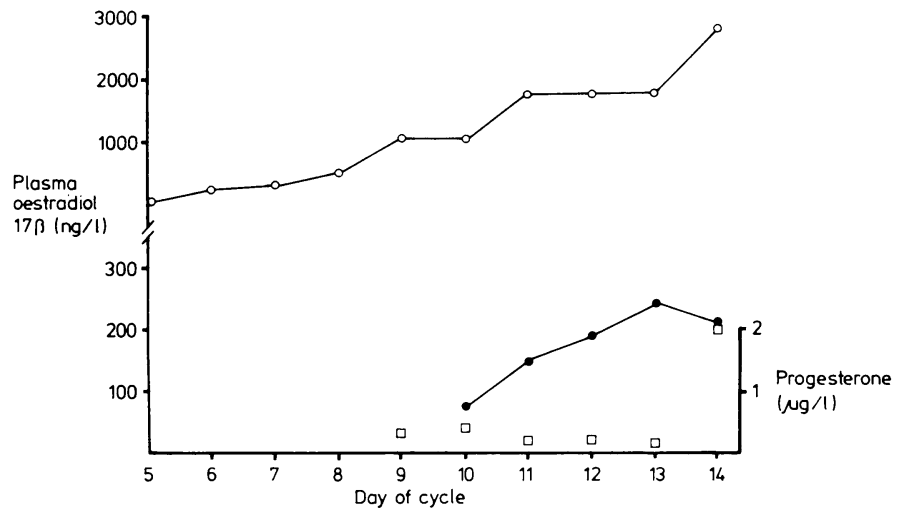

FIG 1 -Changes in plasma oestradiol $17 \beta$ concentration in donor $(0)$ and recipient $(\bullet)$ and change in progesterone in donor $(\square)$ during cycle of in vitro fertilisation. Progesterone concentrations were undetectable in recipient days 10 to 14 .

\section{RECIPIENT}

The recipient was a 38 year old woman who had been married for 19 years and infertile for 18 years and had one adopted child. Her husband had azoospermia, and in 1978 she presented for artificial donor insemination. Investigations of her fertility at that time showed no abnormality; findings in hysterosalpingogram were normal. After six cycles of unsuccessful artificial insemination from a donor, laparoscopy showed a normal patent right tube with abnormal peritubal adhesions on the patent left tube. After laparoscopy in 1979 she became pregnant after the first cycle of artificial insemination but aborted at eight weeks' gestation. A further nine cycles of artificial insemination failed, after which a second laparoscopy revealed a patent but abnormal left tube and an abnormal right tube containing a hole in the ampulla. An intramural fibromyoma $3 \mathrm{~cm}$ in diameter was noted on the posterior wall. In 1981 the patient underwent salpingolysis, closure of the hole in the right tube, and myomectomy. She developed a deep vein thrombosis of the right calf on the second postoperative day; this was treated with heparin and warfarin (Glaxo; Melbourne, Australia) for three months. A further seven cycles of artificial insemination were given, after which a hysterosalpingogram showed patent tubes.

Daily blood samples were obtained from the recipient beginning on day 10 of the menstrual cycle. Plasma was assayed for oestradiol $17 \beta$ and progesterone on days 10 to 14 (fig 1 ) and for luteinising hormone on days 11 to 14 (fig 2 ) after a rise in oestradiol $17 \beta$ concentrations. Urine was collected at home every six hours on days 11 to 14 ; the volume was recorded by the patient and a sample of each collection sent to the laboratory once a day for determination of luteinising hormone concentration. ${ }^{\theta}$ The time of the onset of the surge of luteinising hormone was taken as the first sample of $2000 \mathrm{IU} / 1 / \mathrm{h}$, which occurred at 1500 hours on day 13 (fig 2).

Table I outlines the methods.

\section{INSEMINATION OF OOCYTES}

A semen sample was obtained from the donor's husband one hour before insemination and the spermatozoa washed free of seminal plasma by the addition of $3 \mathrm{ml}$ of culture medium to $1 \mathrm{ml}$ of semen and a single centrifugation for $8 \mathrm{~min}$ at $200 \mathrm{~g}$. Motile spermatozoa

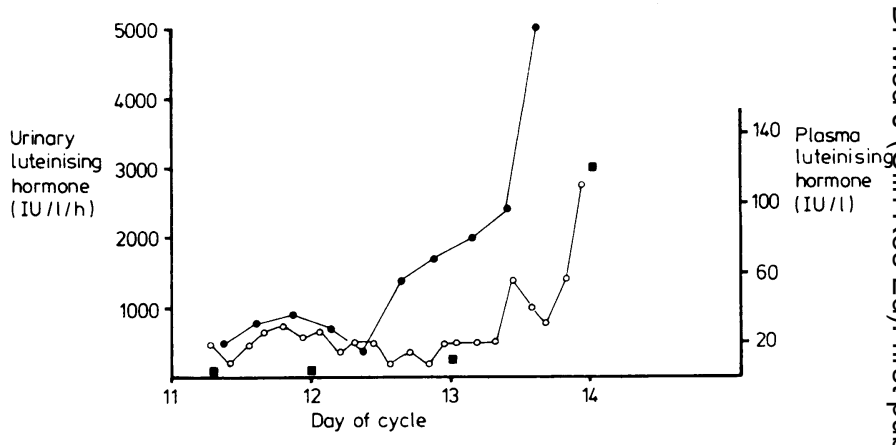

FIG 2-Changes in urinary rate of excretion of luteinising hormone in dono $(O)$ and recipient $(\bullet)$ and plasma luteinising hormone concentration in recipient ( $\boldsymbol{E})$ before laparoscopy and ovulation. Urine samples wer@ collected every three hours from donor and six hours from recipient. Onse出 of luteinising hormone surge 1500 hours day 13 for recipient and 0400 hours day 14 for donor.

TABLE I-Summary of procedure used for in vitro fertilisation and embryo transfero

\begin{tabular}{|c|c|}
\hline $\begin{array}{l}\text { Time between } \\
\text { procedures } \\
\text { (hours) }\end{array}$ & Procedures \\
\hline 23 & $\begin{array}{l}\text { Onset of the donor's surge of luteinising hormone (fig 1) } \\
\text { Laparoscopy: } \\
6 \text { follicles aspirated } \\
5 \text { oocytes recovered }\end{array}$ \\
\hline 7 & $\begin{array}{l}\text { Insemination: } \\
4 \text { oocytes inseminated with donor husband's spermatozo } \\
1 \text { oocyte inseminated with frozen donor spermatozoa }\end{array}$ \\
\hline 12 & $\begin{array}{l}\text { Fertilisation check: } \\
\text { All } 5 \text { oocytes had two pronuclei (fertilised) }\end{array}$ \\
\hline 33 & $\begin{array}{l}\text { Embryos transferred to donor: } \\
\text { One three-cell, two four-cell embryos (one fragmented }\end{array}$ \\
\hline 1 & $\begin{array}{l}\text { Embryo transferred to recipient: } \\
\text { One four-cell embryo }\end{array}$ \\
\hline
\end{tabular}

were allowed to migrate from the sperm pellet into $2 \mathrm{ml}$ culture medium during $20 \mathrm{~min}$ incubation at $37^{\circ} \mathrm{C}$. A total of 60000 motile spermatozoa in $50 \mu \mathrm{l}$ were added to each oocyte in $1 \mathrm{ml}$ of culture medium. Four of the five oocytes recovered from the donor were़ inseminated with spermatozoa of the donor's husband.

A frozen sample of semen, ${ }^{10}$ matched to the recipient's husband's physical characteristics (race, complexion, build, height, eye colour $\overrightarrow{\vec{\sigma}}$ and blood group), was thawed and $0.5 \mathrm{ml}$ of cryopreserved semen added to $3.5 \mathrm{ml}$ of culture medium before centrifugation. A total of 60000 motile spermatozoa in $50 \mu \mathrm{l}$ were added to one oocyte in $1 \mathrm{mb}$ of culture medium.

\section{TREATMENT AND TRANSFER OF EMBRYOS}

Twelve hours after insemination the cumulus cells were removeक्் from the oocytes; all four oocytes inseminated with the semen of the donor's husband had fertilised and the oocyte inseminated with frozen donor semen for the recipient couple had also fertilised. ${ }^{3}$ The oocytes were returned to culture for 33 hours to enable cleavage ando development.

One three-cell and two four-cell embryos were transferred to the donor using an open ended Teflon catheter. ${ }^{6}$ The patient remaineक् in hospital for a further six hours and then returned home. One houf later, a single four-cell embryo was transferred to the recipient, whow returned home after one hour's rest in the position used for embry transfer.

\section{PREGNANCY}

Blood samples were obtained from both the donor and recipient 12 and 14 days after laparoscopy. Table II shows the concentrationsD of plasma progesterone and human chorionic gonadotrophin in both women. There was no indication of pregnancy in the donor, but ank apparently normal pregnancy was initiated in the recipient. Furthe blood samples obtained from the recipient confirmed the establishment of an apparently normal pregnancy up to six weeks after laparoscopy (table II). An ultrasound examination carried out six weeks afte믐 laparoscopy confirmed an apparently normal pregnancy with $\vec{a}$ 
gestation sac of a size within normal limits. Seven weeks after transfer the patient noticed some slight vaginal bleeding, and plasma human chorionic gonadotrophin and progesterone concentrations began to fall (table II). These continued to fall and she finally aborted spontaneously 10 weeks after transfer. Cytogenetic study of the abortus identified a female karyotype with trisomy of chromosome 9 (47, $\mathrm{XX},+9)$

TABLE II-Detection of pregnancy after embryo transfer

\begin{tabular}{|c|c|c|c|c|c|}
\hline \multirow{2}{*}{$\begin{array}{c}\text { No of } \\
\text { days after } \\
\text { laparoscopy }\end{array}$} & \multicolumn{2}{|c|}{ Donor } & \multicolumn{2}{|c|}{ Recipient } & \multirow{2}{*}{$\begin{array}{c}\text { Normal range } \\
\text { HCG } \\
(\mathrm{IU} / \mathbf{1})\end{array}$} \\
\hline & $\begin{array}{l}\text { Progesterone } \\
\quad(\mu \mathrm{g} / 1)\end{array}$ & $\underset{(\mathrm{IU} / \mathrm{I})}{\mathrm{HCG}}$ & $\begin{array}{l}\text { Progesterone } \\
\quad(\mu \mathrm{g} / 1)\end{array}$ & $\begin{array}{l}\text { HCG } \\
(I U / 1)\end{array}$ & \\
\hline 12 & $2 \cdot 9$ & $0 \cdot 4$ & 40 & 23 & \\
\hline 14 & 0.7 & $0 \cdot 1$ & 31 & 36 & $24-80$ \\
\hline 15 & & & 41 & $\begin{array}{r}59 \\
855\end{array}$ & \\
\hline $\begin{array}{l}22 \\
29\end{array}$ & & & $\begin{array}{l}31 \\
37\end{array}$ & $\begin{array}{r}855 \\
6400\end{array}$ & $\begin{array}{c}400-3400 \\
1800-16000\end{array}$ \\
\hline 33 & & & 21 & 10600 & $6000-49000$ \\
\hline 40 & & & 26 & 26600 & $7000-75000$ \\
\hline 47 & & & 18 & 9200 & $20000-100000$ \\
\hline 51 & & & 10 & 5000 & \\
\hline 54 & & & 7 & 2500 & \\
\hline 57 & & & 8 & 1900 & \\
\hline 63 & & & 9 & 450 & \\
\hline 67 & & & 1 & 57 & \\
\hline
\end{tabular}

HCG = Human chorionic gonadotrophin.

\section{Discussion}

This is the first successful attempt to transfer an embryo from a donor to recipient in the human, though it is a common procedure in animal breeding. Several elements in this report are important for human infertility and for the technique of in vitro fertilisation and embryo transfer. Firstly, we have shown that it is possible to transfer embryos successfully between patients who have a surge of luteinising hormone within 24 hours of each other. In animals successful embryo transfer depends on the degree of synchronisation of ovulation. ${ }^{11}$ In our study the recipient's surge of luteinising hormone began about 13 hours before the donor's and she presumably would have ovulated a similar number of hours earlier. The techniques used to determine the onset of the surge of luteinising hormone in the recipient appear to give the appropriate precision necessary to synchronise the donor and recipient.

Secondly, the failure of pregnancy in the donor who had three apparently normal embryos transferred compared with the initiation of successful pregnancy in the recipient who had a single embryo transferred may enable us to separate the relative contributions of embryo viability and uterine receptivity to the pregnancy rate of transferred embryos. Patients whose ovulatory cycles were stimulated with clomiphene citrate ${ }^{12}$ or gonadotrophins ${ }^{13}$ may have a reduced capacity for implantation because of inadequate or abnormal uterine response and a reduced length of the luteal phase. The donor in the present case had very low plasma progesterone concentrations 12 days after laparoscopy (table II). If pregnancy rate is significantly higher in spontaneously ovulating recipients, having transferred the same number of embryos, this would indicate that uterine receptivity for embryo development is reduced by the treatments used to obtain multiple oocytes for in vitro fertilisation. The contribution of embryo viability to pregnancy rate may be assessed by the relative increase in pregnancy rate and the number of fetuses developing with the number of embryos transferred. Our present data would indicate that a relatively small increase in pregnancy rate occurs with the transfer of three or four embryos compared with that with two embryos. ${ }^{14}$ Pregnancy rate increases after the transfer of twin compared with single embryos, though our results suggest this is smaller than previously reported and closer to those obtained by Edwards and Steptoe. If embryo viability has a limited contribution to increased pregnancy rate, the possible pregnancy rate that could be achieved by in vitro fertilisation may be governed by uterine receptivity.
Thirdly, the successful transfer of a donated embryo enables the treatment of a new group of infertile patients. This includes patients who are known to carry inheritable genetic disease, those with severe pelvic disease or abnormality preventing access to the ovaries for conventional oocyte recovery ${ }^{15}$ or ultrasonically guided follicular aspiration, ${ }^{16}$ those whose ovaries do not respond to stimulation therapy, and those patients at risk because of treatment and procedures used for in vitro fertilisation-for example, coagulation disorders and previous thromboembolic disease.

The recipient in our study had had a previous deep vein thrombosis and the thromboembolic risk resulting from repeated laparoscopies contraindicated the procedure of in vitro fertilisation, as cardiovascular homoeostasis may be affected by the pneumoperitoneum and the use of prolonged anaesthesia. ${ }^{17} 18$ It may be argued that the risk of pregnancy with such a condition should exclude her from even donated embryo transfer, but given the full explanation of such risks the patient and her husband wished to proceed. This is analogous to the situation of a woman proceeding to natural conception, the importance of the previous thromboembolic episode in determining the risk in a future pregnancy having been explained to her and the patient then deciding whether to take this risk. In 15 women who became pregnant after previous thromboembolic phenomena, three developed thrombosis. ${ }^{19}$ Subcutaneous heparin has been used to prevent thromboembolic disease in pregnant women at risk, ${ }^{20}$ although Hirsh et al recommended careful observation without anticoagulants in pregnant women who have had only a single episode of thromboembolism before pregnancy. ${ }^{21}$ The patient was not given anticoagulants.

Other clinical characteristics of the case include the condition of azoospermia in the recipient's husband and the failure of the wife to conceive after 22 cycles of artificial insemination with donor semen. Conception was prevented by some undiagnosed condition, which could have included some abnormality of ovulation and oocyte release or transport along the fallopian tubes or genetic abnormality of the oocyte. The pregnancy was certainly initiated by donated embryo transfer because of the husband's azoospermia, the duration of infertility, and the failure of artificial insemination. This was the second transfer of a donated embryo to the recipient, the first was not successful in initiating pregnancy. It is also of interest to note that the developing embryo is genetically foreign to the recipient, having none of the recipient's own genes. In animal experiments this does not effect the survival of pregnancy provided that embryo transfers are within the same species.

Previous reports of conceptuses with trisomy of chromosome 9 indicate abortion occurs at 68 to 104 days (menstrual age) in women of 27 to 42 years of age. ${ }^{22}$ The mechanism of origin may be errors of the first or second meiotic division in either the male or females gametes. It is not known whether a higher incidence of trisomy is associated with in vitro fertilisation. In our own studies the only ectopic pregnancy resulting from in vitro fertilisation was identified as a trisomy of chromosome 21 . No other chromosome abnormalities have been identified.

This was the donor's first attempt to conceive by in vitro fertilisation and embryo transfer. Several factors may have reduced the chance of pregnancy in her case. Firstly, her husband is oligospermic and his sperm concentrations are consistently below $10 \times 10^{6}$ spermatozoa $/ \mathrm{ml}$ semen. Fertilisation rate is normally lower in such cases ${ }^{23}$ and the chance of pregnancy after embryo transfer may also be reduced. Secondly, the wife is 42 years old, which may also reduce the chance of pregnancy after embryo transfer, though we have been unable to demonstrate such an effect in our studies. Thirdly, the subserous fibromyoma could be a possible factor in her infertility.

New ethical issues, apart from those associated with in vitro fertilisation, are the use of donor material, both sperm and oocyte, and the effect, if any, on the donors who have not become pregnant. The ethics committee of the Queen Victoria Medical Centre allowed oocyte donation provided that the donor and recipient remained anonymous, thus preventing the 
possibility of interaction or argument between the genetic and rearing parents. This ignores the possible need of the child to identify the genetic parents, as some adopted children have desired. Oocyte donation differs in one way from sperm donation in so far as the law tends to identify the mother as the person who is pregnant and gives birth, whereas the father is identified as the person who provides the spermatozoa. ${ }^{24}$ In the current pregnancy both sperm and egg donors were used. While this makes identification of the patients in a legal context more complex it may have one advantage. Connolly, a moral theologian, postulates that if both the oocyte and sperm are donated, any possible psychological ill effects on the marriage may be less, as neither of the infertile couple are genetic parents and both are rearing parents so that the contribution of the couple to the conception is more balanced than in artificial insemination by a donor. ${ }^{25}$

The possibility of resentment among donors who have themselves not become pregnant and who have given oocytes in the cycle in which the recipient woman became pregnant may arise if the duration of gestation of the recipient's pregnancy becomes known. This information would be suppressed. As more pregnancies occur the problem is less likely to arise, but in asking women to donate their oocytes it may be worth while pointing out the possibility that their original motivation to help someone else may increase their disappointment and lead to resentment should their own attempt fail.

\section{References}

1 Trounson AO, Leeton JF, Wood C, Webb J, Wood J. Successful human pregnancies by in vitro fertilization and embryo transfer in the controlled ovulatory cycle. Science $1981 ; 212: 681-2$.

2 Trounson A, Conti A. Research in human in vitro fertilization and embryo transfer. $\mathrm{Br} M e d \mathcal{F} 1982 ; \mathbf{2 8 5}: 244-8$.

3 Trounson AO, Mohr LR, Wood C, Leeton JF. Effect of delayed insemination on in vitro fertilization, culture and transfer of human embryos. f Reprod Fertil 1982;64:285-94.

4 Wood C, Trounson A, Leeton J, et al. A clinical assessment of nine pregnancies resulting from in vitro fertilization and embryo transfer. Fertil Steril 1982;35:502-8.

5 Wood C, Trounson AO, Leeton JF, et al. Clinical features of eight pregnancies resulting from in vitro fertilization and embryo transfer. Fertil Steril $1982 ; 38: 22-9$.

${ }^{6}$ Leeton J, Trounson A, Jessup D, Wood C. The technique for human embryo transfer. Fertil Steril 1982;38:156-61.

7 Trounson AO, Mohr LR, Pugh PA, Leeton JF, Wood EC. The deepfreezing of human embryos. In: Proceedings of third world congress of human reproduction. Berlin, 1981. Amsterdam: Excerpta Medica, 1981: 367. (Abstract.)
${ }^{8}$ Trounson A. In vitro fertilization and embryo transfer. In: Wood C, Trounson $\mathrm{A}$, eds. In vitro fertilization and embryo transfer. London: Churchill Livingstone (in press).

9 Trounson AO, Herreros M, Burger $\mathrm{H}$, Clarke I. The precise detection of ovulation using a rapid radioimmunoassay of urinary LH. Proceedings C of the Endocrine Society of Australia 1980;23:73.

${ }^{10}$ Mahadevan $M$, Trounson AO. Effect of cryoprotective media and dilution methods on the preservation of human spermatozoa. Andrologia 1982 (in press).

11 Rowson LEA, Moor RM. Embryo transfer in the sheep: the significance $\mathbb{D}^{\circ}$ of synchronizing oestrus in the donor and recipient animals. $\mathcal{F} \operatorname{Reprod} \Pi$ Fertil 1966;11:207-12.

12 Trounson AO, Leeton JF. The endocrinology of clomiphene stimulation. In: Edwards RG, Purdy JM, eds. Human conception in vitro. London: Academic Press, 1982:51-5.

${ }^{13}$ Edwards RG, Steptoe PC, Purdy JM. Establishing full-term human pregnancies using cleaving embryos grown in vitro. Brf Obstet Gynaecol $\frac{\bar{\sigma}}{\frac{5}{7}}$
$1980 ; 87: 737-56$.

14 Trounson AO. Factors controlling normal embryo development and implantation of human oocytes fertilized in vitro. In: Beier $H M$, Lindner HR, eds. Fertilization of the human egg in vitro: biological basis and clinical applications. Berlin: Springer-Verlag (in press).

15 Wood C, Leeton JF, McTalbot J, Trounson AO. Techniques for collecting mature human oocytes for in vitro fertilization. Br $\mathcal{F}$ Obstet Gynaecol $\vec{\omega}$ $1981 ; 88: 756-60$.

${ }^{16}$ Lenz S, Lauritsen JG, Kjellow M. Collection of human oocytes for in vitro fertilization by ultrasonically guided follicular puncture. In Rolland R, van Hall EV, Hillier SG, McNatty KP, Schoemaker J, eds. Follicular maturation and ovulation. Amsterdam: Excerpta Medica, 1982:338-41. (International Congress Series No 560.)

17 Hodgson C, McClelland RMA, Newton JR. Some effects of the peritoneal insufflation of carbon dioxide at laparoscopy. Anaesthesia 1970;25:382-9.

${ }^{18}$ Smith I, Benzie RJ, Gordon NLM, Kelman GR, Swapp GH. Cardiovascular effects of peritoneal insufflation of carbon dioxide for laparo- $\mathcal{G}$ scopy. Br Med F 1971 ; iii:410-1.

19 Badaracco MA, Vessey MP. Recurrence of venous thrombo-embolic disease and use of oral contraceptives. $B r$ Med $\mathcal{F} 1974 ; \mathrm{i}: 215-8$.

20 Bonnar J. Long-term self administered heparin therapy for prevention and treatment of thrombo-embolic complications in pregnancy. In: Kahkar VV, Thomas D, eds. Heparin chemical and clinical usage. London: Academic Press, 1976:247.

${ }^{21}$ Hirsh J, Cade JF, O'Sullivan EF. Clinical experience with anticoagulant $\overrightarrow{0}$ therapy during pregnancy. $\mathrm{Br} M e d \mathcal{F} 1970 ; \mathrm{i}: 270-3$.

${ }^{22}$ Hassold T, Chen N, Funkhouser J, et al. A cytogenetic study of $1000^{\circ}$ spontaneous abortions. Ann Hum Genet 1980;44:151-78.

${ }^{23}$ Mahadevan M, Baker G. Assessment and preparation of semen for in vitro fertilization. In: Wood $\mathrm{C}$, Trounson $\mathrm{AO}$, eds. Clinical in vitro fertilization. London: Springer (in press).

${ }^{24}$ Mason M. Abnormal conception. The Australian Law Fournal 1982;56: $\frac{\mathrm{Q}}{\mathbb{Q}}$ 347-57.

25 Connolly $T$. Theological aspects of in vitro fertilisation and embryo $\overrightarrow{\overrightarrow{0}}$ transfer. In: Proceedings of the Australian and New Zealand Association 3 for the Advancement of Science conference. Sydney: Macquarie University (in press).

(Accepted 1 February 1983)
ENGLISH TOBACCO rises up with a round thick stalk, about two feet high, whereon do grow thick, flat green leaves, nothing so large as the other Indian kind, somewhat round pointed also, and nothing dented about the edges. The stalk branches forth, and bears at the tops divers flowers set on great husks like the other, but nothing so large: scarce standing above the brims of the husks, round pointed also, and of a greenish yellow colour. The seed that follows is not so bright, but larger, contained in the like great heads. The roots are neither so great nor woody; it perishes every year with the hard frosts in Winter, but rises generally from its own sowing.

This came from some parts of Brazil, as it is thought, and is more familiar in our country than any of the other sorts; early giving ripe seed, which the others seldom do. It flowers from June, sometimes to the end of August, or later, and the seed ripens in the mean time.

It is a martial plant. It is found by good experience to be available to expectorate tough phlegm from the stomach, chest, and lungs. The juice thereof made into a syrup, or the distilled water of the herb drank with some sugar, or without, if you will, or the smoak taken by a pipe, as is usual, but fainting, helps to expel worms in the stomach and belly, and to ease the pains in the head, or megrim, and the griping pains in the bowels. It is profitable for those that are troubled with the stone in the kidneys, both to ease the pains by provoking urine, and also to expel gravel and the stone engendered therein, and hath been 을 found very effectual to expel windiness, and other humours, which $N$ cause the strangling of the mother. The seed hereof is very effectual to expel the tooth ache, and the ashes of the burnt herb to cleanse the gums, and make the teeth white. The herb bruised and applied to the place grieved with the king's evil, helps it in nine or ten days effectu- O ally. Monardus saith, it is a counter poison against the biting of any $\mathbf{\omega}$ venomous creature, the herb also being outwardly applied to the hurt 0 place. The distilled water is often given with some sugar before the fit of an ague, to lessen it, and take it away in three or four times using. If the distilled faeces of the herb, having been bruised before the distillation, and not distilled dry, be set in warm dung for fourteen days, and afterwards be hung in a bag in a wine cellar, the liquor that distills therefrom is singularly good to use in cramps, aches, $\underset{\oplus}{\stackrel{P}{+}}$ the gout and sciatica, and to heal itches, scabs, and running ulcers, cankers, and all foul sores whatsoever. The juice is also good for all the said griefs, and likewise to kill lice in children's heads. The green herb bruised and applied to any green wounds, cures any fresh wound or cut whatsoever: and the juice put into old sores, both cleanses 응 and heals them. There is also made hereof a singularly good salve to help imposthumes, hard tumours, and other swellings by blows and falls. (Nicholas Culpeper (1616-54) The Complete Herbal, 1850.) 